\title{
Nutritional status and functional capacity of community-dwelling elderly in southern Laos
}

\author{
Joweria Nambooze $\cdot$ Miho Fujimura \\ Tsukasa Inaoka
}

Received: 22 October 2013/Accepted: 25 October 2013/Published online: 12 November 2013

(C) The Japanese Society for Hygiene 2013

\begin{abstract}
Objectives The aim of this study was to assess the nutritional status and functional capacity of 144 community-dwelling elderly in three rural ethnic groups, namely, the Oy, the Brau and the Lao, of southern Laos.

Methods The Mini nutritional assessment (MNA) questionnaire and Determine Your Nutritional Health checklist were used to assess nutritional status. The Barthel Activities of Daily Living questionnaire and Lawton and Brody's Instrumental Activities of Daily Living questionnaire were used to assess the functional capacity of the respondents.

Results The MNA score results indicated that $92.5 \%$ of Oy respondents, $85.4 \%$ of Brau respondents and $60 \%$ of Lao respondents were malnourished. Analysis of variance tests showed that the MNA scores of the Oy and Lao ethnic groups and of the Brau and Lao ethnic groups were significantly different ( both $p<0.01$ ), but that there was no significant difference between the MNA scores of the Oy and Brau ethnic groups $(p>0.05)$. In terms of functional capacity, $47.2 \%$ of Oy respondents, $43.9 \%$ of Brau respondents and $20 \%$ of Lao respondents had limitations in their activities of daily living, whereas $98.1 \%$ of $\mathrm{Oy}$ respondents, $97.6 \%$ of Brau respondents and $86 \%$ of Lao
\end{abstract}

\footnotetext{
J. Nambooze

The United Graduate School of Agricultural Sciences,

Kagoshima University, Kagoshima, Japan

J. Nambooze $(\bowtie) \cdot$ M. Fujimura · T. Inaoka

Department of Human Ecology, Faculty of Agriculture, Saga

University, 1 Honjo Machi, Saga 840-0052, Japan

e-mail: joweyrocs@yahoo.com

M. Fujimura

e-mail: fujimum@cc.saga-u.ac.jp

T. Inaoka

e-mail: inaoka@cc.saga-u.ac.jp
}

respondents had limitations in their instrumental activities of daily living. Body mass index, reduced appetite, number of meals consumed daily and presence of common diseases predicted nutritional status in all three ethnic groups; the remaining factors differed by ethnicity. This result implies that ethnic differences and other factors, such as location of the village, services, resources within the village and respondents' lifestyles, can affect nutritional status.

Conclusions Because predictors of nutritional status varied by ethnicity, there is a need for area-specific interventions aimed at improving the quality of life of the elderly in these areas.

Keywords Mini nutritional assessment - Activities of daily living - Instrumental activities of daily living . Community-dwelling elderly $\cdot$ Functional capacity

\section{Introduction}

Good nutrition is beneficial for both optimal health and the ability to resist and recover from disease, while malnutrition leads to dependency [1]. Dependency interferes with health and the quality of life (QOL) not only of the elderly but also of relatives and healthcare providers [2]. The nutritional status of individuals results from a complex interaction between personal and environmental factors [3]. Especially among the elderly, personal factors, such as functional capacity, which represents an individual's capacity to perform daily activities in the physical, psychological, social and spiritual domains of life [4], are vital for good health. Studies have uncovered a relationship between nutritional status and functional capacity in the elderly $[3,5,6]$, especially among the hospitalised elderly; 
however, in our study we focused on the communitydwelling elderly.

Laos, one of the world's least developed countries, is landlocked and mountainous, with significant parts of the country still inaccessible by roads [7]. More than twothirds of Laos' 6.9 million population live in rural areas and depend on agriculture for livelihood. Poverty, cultural responsibility, age and diseases have caused children and the elderly in rural parts of Laos to depend on family members for food and support. This inability to fend for oneself has placed these individuals at high risk for malnutrition; as a result, they are vulnerable. A number of studies have been carried out on the nutritional status of children in Laos [8, 9]. However, insufficient data are available on the nutrition and health status of the elderly. The health status of the elderly has also not been well documented in many of the health guidelines in Laos, including the recently published National Health Statistic Report of 2012. This is unsettling, given that elderly are becoming an increasingly important proportion of the population in many developing countries.

The percentage of elderly people aged $\geq 65$ years in Laos is expected to increase from $5 \%$ in 2000 to $14 \%$ in 2050 [10]. With life expectancy continuing to increase, the size of this age group will keep growing. It is therefore important to assess the nutritional status of older people due to the role nutrition plays in ensuring a better QOL and its association with functional ability [11, 12]. Assessment of nutritional status also increases the odds of the early detection and treatment of malnutrition.

Children and the elderly are not the only at-risk groups; people who belong to ethnic minority groups are also vulnerable to malnutrition. In comparison with the ethnic majority groups, ethnic minority groups tend to live in poverty. Laos is a diverse nation with many ethnic groups and languages. According to the Country Technical Notes on Indigenous Peoples' Issues report by the International Fund for Agricultural Development [13], Laos has the most ethnically diverse population on mainland Southeast Asia, with 49 ethnic groups. The Lao Loum (lowland Lao) group, comprising ethnic groups such as the Lao, Lue and $\mathrm{Lu}$, constitutes the majority of the Lao population (approx. $68 \%$ ). Lao Loum live along the banks of the many rivers of Laos and generally occupy areas where agriculture is more productive and the infrastructure is more developed. Conversely, the Lao Theung group, which consists of minority tribes, such as the Brau, Lawain, Oy and Pakoh, accounts for approximately $22 \%$ of the national population. They are located in the southern area of the country in the mountainous and remote areas. Ethnic minority groups still experience poverty, and many of them can be classified as extremely poor. Most of these ethnic minority groups can only produce rice sufficient for 7-9 months of annual consumption, making them vulnerable to malnutrition.

The aim of this study was, therefore, to assess the nutritional status and functional capacity of the community-dwelling elderly in two ethnic minority groups and a majority group in southern Laos. An additional aim was to identify the predictors of nutritional status in these groups. To date, there has been minimal research carried out on the health status of elderly in this area. The overall purpose of this study was therefore to clarify the current health and nutritional situation of the elderly, especially within minority populations in southern Laos.

\section{Subjects and methods}

Study area and sample size

A cross-sectional study was carried out on 144 elderly (age $>65$ years) male and females residents of three villages in Laos, i.e., Somsouk village in Sanamxai district, Phouhome village in Phouvong district and Vatluong village in Xaysetha district. All three villages are in Attapeu province, which is one of the poorest provinces in Laos.

Somsouk village is located in the rural and mountainous parts of Attapeu province, approximately $1 \mathrm{~h}$ from the town centre. This village has a population of approximately 1,092 people distributed in 174 households. Agriculture is the main source of income; however, some villagers have found part-time employment at a Vietnamese-owned rubber plantation locally known as "Yampala". The Oy, an ethnic minority group believed to have originated from the highlands in the 1960s and 1970s, are the main inhabitants of Somsouk village. The Oy subsist on lowland rice.

Phouhome village has a population of 825 people distributed in 171 households. It is located in the rural and mountainous parts of Attapeu province, approximately 1.5 $\mathrm{h}$ from Attapeu city centre. Phouhome is inhabited mainly by the Brau ethnic minority group (95\%), who are said to have originated from the highland areas in the 1960s and 1970s, and the Lao ethnic group (5\%). The main source of livelihood in this village is also agriculture. The people in this village depend on both lowland and upland rice for food, and only a few of them work at the Yampala rubber plantation.

The Vatluong village is inhabited mainly by the Lao ethnic group-specifically, the biggest ethnic group, the Lao Loum. It has a population of approximately 1,726 people in 253 households. Unlike Somsouk and Phouhome, Vatluong village is located in the urban part of Attapeu province, approximately $30 \mathrm{~min}$ from the town centre. Most people in this village are fully engaged in rice farming because there are two planting seasons (one using 
irrigation and the other using the annual rainy season). As a result, only a few people from this village work part-time.

\section{Data collection}

In 2012, data were collected from 144 elderly subjects: 53 from Somsouk village, 41 from Phouhome village and 50 from Vatluong village. The villages were selected with the help of staff from the Ministry of Health, Attapeu branch. All of the elderly residing in these villages who could be measured and were able to respond to the questions asked at the time of study were included in our study. The same respondents were included in another study in 2013 to reassess their nutritional status. Unfortunately, between the first and second studies three of the respondents had died, one was very ill and 14 had relocated to different villages, reducing the sample size to 126 .

Nutritional status data were collected by the Mini nutritional assessment (MNA) questionnaire and the Disease, Eating poorly, Tooth loss, Economic hardship, Reduced social contact, Multiple medicines, Involuntary weight loss, Needs assistance in self-care, Elderly years above age 80 (DETERMINE) Your Nutritional Health checklist. The MNA questionnaire, which is designed for geriatric patients, has a high sensitivity $(96 \%)$ and specificity $(98 \%)$ [14]. It is composed of anthropometric measurements (weight, height and weight loss), a global assessment (questions related to lifestyle, medication and mobility), a dietary questionnaire (number of meals, protein, fruits and vegetable intake and autonomy of feeding) and a subjective assessment (self-perception of health and nutrition). The maximum score of the MNA is 30; it can distinguish between elderly people with adequate nutritional statuses (MNA $>24$ points), those at risk of malnutrition (MNA 17-23.5 points) and malnutrition (MNA $<17$ points) [15]. Studies carried out using this questionnaire in other developing countries have found it to be useful and accurate [16-18].

The 'Determine Your Nutritional Health' checklist was developed as part of the U.S. Nutrition Screening Initiative (NSI), a collaborative effort between the American Dietetic Association, the American Academy of Family Physicians and the National Council on the Ageing [19]. It consists of ten items that add up to 21 points. The items include questions on disease, eating poorly, tooth loss or mouth pain, economic hardships and multiple medicines, etc. In total, $0-2$ points indicate a good nutritional status, 3-5 points indicate moderate nutritional risk and $>6$ points indicate a high nutritional risk.

Functional capacity was assessed by the activities of daily living (ADL) and instrumental activities of daily living (IADL) [20, 21]. ADL were assessed using the Barthel Index ADL questionnaire, which consists of ten items, i.e., bowel movement, bladder continence, grooming, toilet use, feeding, transferring in and out of bed, mobility, dressing, walking up the stairs and bathing. IADL, on the other hand, were assessed using the Lawton and Brody IADL questionnaire, which consists of eight items, namely, the ability to use the phone, shopping, food preparation, housekeeping, laundry, mode of transportation, responsibility for one's own medication and ability to handle finances. Housekeeping and laundry were combined into one question, and responsibility for one's own medication was omitted because the researchers assumed that only a limited number of the respondents were taking Western medicine. The IADL questionnaire used thus consisted of six items. The data were divided into two categories: with limitations and without limitations, respectively. The former category was defined as those individuals having difficulties in carrying out one or more of the tasks, and the latter reflected no problems whatsoever in carrying out all of the tasks.

Data on the socioeconomic situation and geriatric depression scale (GDS) were collected through a structured questionnaire that was prepared by the researchers and a geriatric depression scale questionnaire, respectively. Focus group discussions were also held to find out general information about the ethnic groups and study areas.

All questionnaires were translated into the Lao language before data collection, and all interviews were carried out in the Lao language to ensure that the survey ran smoothly. This study was approved by the National Ethical Committee for Health Research, Ministry of Health in Laos. All study participants were informed of the purpose of the study, and a verbal consent was received.

\section{Statistical analysis}

Data analysis was carried out with the SPSS software package ver. 20 (SPSS Inc., Chicago, IL). One-way analysis of variance (ANOVA) was used to determine whether there was statistical significance between various attributes within the three ethnic groups, Spearman's correlation was used to identify variables that were significantly correlated with nutritional status in each ethnic group and logistic regression analyses were carried out to assess predictors of nutritional status in each ethnic group. A significance probability value of $p<0.05$ was used.

\section{Results}

General characteristics of the respondents

The general characteristics of the respondents based on their ethnicity are shown in Table 1. Most of the 
respondents in all three ethnic groups were in the age group 65-74 years, and there were more female respondents than males. Many of the respondents in all three groups were married and living with family members. Most of the respondents from the Oy and the Brau consumed two or fewer meals daily (62.3 and $73.2 \%$, respectively), whereas only $16 \%$ of Lao respondents consumed two meals or fewer daily. The level of illiteracy was quite high among

Table 1 General characteristics of the respondents

\begin{tabular}{|c|c|c|c|}
\hline Variables & Oy $(n=53)$ & Brau $(n=41)$ & Lao $(n=50)$ \\
\hline \multicolumn{4}{|l|}{ Age (years) } \\
\hline $65-74$ & $25(47.2)$ & $28(68.3)$ & $30(60.0)$ \\
\hline $75-84$ & $19(35.8)$ & $8(19.5)$ & $13(26.0)$ \\
\hline$>85$ & $9(17.0)$ & $5(12.2)$ & $7(14.0)$ \\
\hline \multicolumn{4}{|l|}{ Gender } \\
\hline Male & $24(45.3)$ & $16(39.0)$ & $15(30.0)$ \\
\hline Female & $29(54.7)$ & $25(61.0)$ & $35(70.0)$ \\
\hline \multicolumn{4}{|l|}{ Marital status } \\
\hline Married & $29(54.7)$ & $22(53.7)$ & $19(38.0)$ \\
\hline Others & $24(45.3)$ & $19(46.3)$ & $31(62.0)$ \\
\hline \multicolumn{4}{|l|}{ Number of meals } \\
\hline$<2$ meals & $33(62.3)$ & $30(73.2)$ & $8(16.0)$ \\
\hline$>2$ meals & $20(37.7)$ & $11(26.8)$ & $42(84.0)$ \\
\hline \multicolumn{4}{|l|}{ Education level } \\
\hline None & $45(84.9)$ & $35(85.4)$ & $24(48.0)$ \\
\hline Primary and above & $8(15.1)$ & $6(14.6)$ & $26(52.0)$ \\
\hline \multicolumn{4}{|l|}{ Living conditions } \\
\hline With family & $46(86.8)$ & $36(87.8)$ & $47(94.0)$ \\
\hline Alone & $7(13.2)$ & $5(12.2)$ & $3(6.0)$ \\
\hline \multicolumn{4}{|l|}{ Food taboos } \\
\hline Yes & $11(20.8)$ & $8(19.5)$ & $20(40.0)$ \\
\hline No & $42(79.2)$ & $33(80.5)$ & $30(60.0)$ \\
\hline \multicolumn{4}{|l|}{ GDS } \\
\hline Normal & $0(0.0)$ & $0(0.0)$ & $3(6.0)$ \\
\hline Depressed & $53(100)$ & $41(100)$ & $47(94.0)$ \\
\hline \multicolumn{4}{|l|}{ BMI $\left(\mathrm{kg} / \mathrm{m}^{2}\right)$} \\
\hline$<19$ & $34(64.2)$ & $29(70.7)$ & $13(26.0)$ \\
\hline$>19<21$ & $15(28.3)$ & $8(19.5)$ & $16(32.0)$ \\
\hline $21-23$ & $3(5.7)$ & $2(4.9)$ & $13(26.0)$ \\
\hline$>23$ & $1(1.9)$ & $2(4.9)$ & $8(16.0)$ \\
\hline \multicolumn{4}{|l|}{ Common diseases } \\
\hline Yes & $31(58.5)$ & $31(75.6)$ & $36(72.0)$ \\
\hline No & $22(41.5)$ & $10(24.4)$ & $14(28.0)$ \\
\hline \multicolumn{4}{|c|}{ Neuropsychological stress } \\
\hline Yes & $36(67.9)$ & $32(78.0)$ & $21(42.0)$ \\
\hline No & $17(32.1)$ & $9(22.0)$ & $29(58.0)$ \\
\hline
\end{tabular}

GDS Geriatric depression scale, BMI Body mass index

Data are presented as the number (of respondents) with the percentage in parenthesis the respondents, representing $84.9 \%$ of Oy respondents, $85.4 \%$ of Brau respondents and $48 \%$ of Lao respondents who had received no formal education at all. Based on the GDS scores, the level of depression among the respondents was quite high (100\% for both the Oy and the Brau and $94 \%$ for the Lao). Of the respondents from the Oy and Brau, 64.2 and $70.7 \%$, respectively, had body mass index (BMI) scores of $<19$, whereas only $26 \%$ of those from the Lao had such low BMI scores. Common diseases, such as hypertension, stomach ulcers, arthritis, diabetes and tuberculosis were more prevalent in the Brau and the Lao than in the Oy.

\section{Nutritional status}

The nutritional status of the elderly, based on MNA scores, is shown in Fig. 1. From the results, $92.5 \%$ of $\mathrm{Oy}$ respondents, $85.4 \%$ of Brau respondents and $60 \%$ of Lao respondents were malnourished. Only $2 \%$ of the respondents had a normal nutritional status, and these were all from the Lao ethnic group. The mean scores were $13 \pm 2.5,12.5 \pm 3.4$ and $16.7 \pm 3.4$ for the Oy, Brau and Lao respondents, respectively. ANOVA tests showed a significant difference between the MNA scores of the Oy and the Lao $(p<0.01)$ and between those of the Brau and the Lao $(p<0.01)$, but not between those of the Oy and the Brau $(p>0.05)$.

To confirm these results for the prevalence of malnutrition, the DETERMINE Your Nutritional Health checklist was used for 126 of the 144 respondents. Figure 2 shows the DETERMINE scores based on ethnicity. These results reveal that $81.6 \%$ of the Oy respondents, $91.9 \%$ of the Brau respondents and $50 \%$ of the Lao respondents were at a high risk for malnutrition. The mean DETERMINE

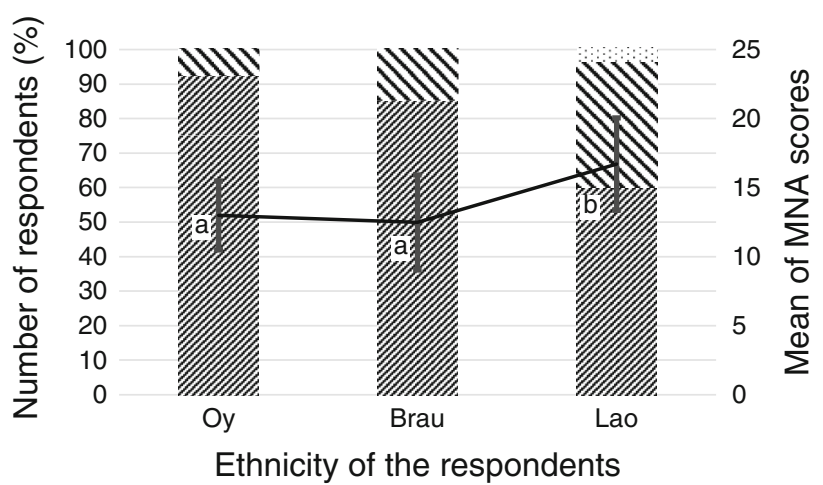

Malnourished WA trisk $\quad \therefore$ Normal $\quad$ Mean with SD

Fig. 1 Means of Mini nutritional assessment (MNA) questionnaire scores and percentage of number of respondents based on ethnicity of the respondents $(n=144)$. Same letters within the graph indicate that the means do not differ significantly 


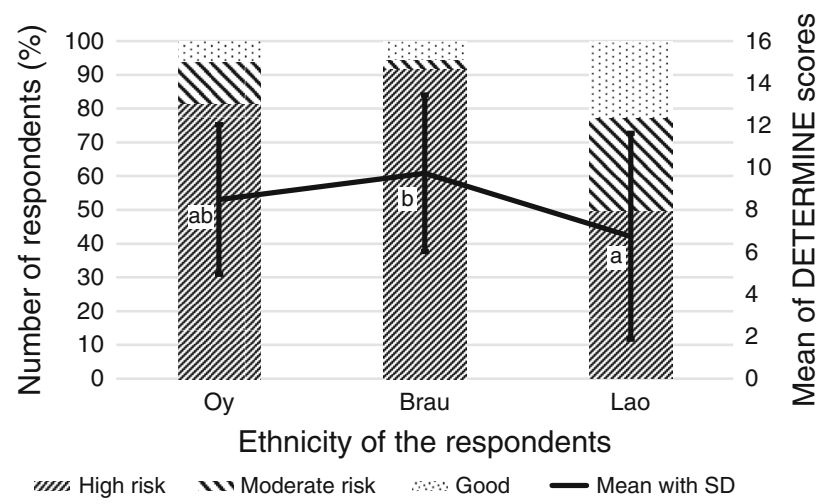

Fig. 2 Means of DETERMINE scores and percentage number of respondents based on ethnicity of the respondents $(n=126)$. Same letters within the graph indicate that the means that do not differ significantly. DETERMINE Disease, Eating poorly, Tooth loss, Economic hardship, Reduced social contact, Multiple medicines, Involuntary weight loss, Needs assistance in self-care, Elderly years above age 80 Your Nutritional Health checklist

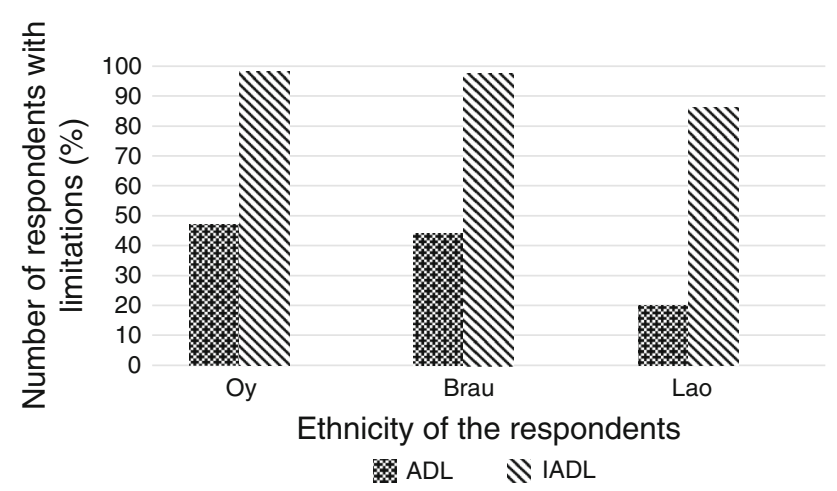

Fig. 3 Activities of daily living $(A D L)$ and instrumental activities of daily living $(I A D L)$ scores of the respondents with limitations based on ethnicity

scores were $8.5 \pm 3.6,9.7 \pm 3.7$ and $6.8 \pm 4.9$ for the $\mathrm{Oy}$, Brau and Lao respondents, respectively. Similar to the MNA results, there was a significant difference between the DETERMINE scores of the Brau and the Lao $(p<0.01)$; however the DETERMINE scores between the $\mathrm{Oy}$ and Brau and between the Oy and Lao were not significantly different $(p>0.05)$. A significant correlation was observed between MNA scores and DETERMINE scores $(r=-0.339, p<0.01)$.

Functional capacity

Figure 3 shows the functional capacity of the respondents. Only "with limitation" data are shown.

From these findings, $47.2 \%$ of the respondents from the Oy, $43.9 \%$ from the Brau and $20 \%$ from the Lao had limitations in their ADL, whereas $98.1 \%$ of Oy respondents, $97.6 \%$ of Brau respondents and $86 \%$ of Lao respondents had limitations in their IADL. The mean ADL scores were $16.9 \pm 2.1,18.6 \pm 0.5$ and $17.8 \pm 1.6$ for the Oy, Brau and Lao, respectively, while the mean IADL scores were $7.0 \pm 1.8,7.2 \pm 2.1$ and $6.9 \pm 2.2$, respectively. An ANOVA test revealed a significant difference between the ADL scores of the Oy and the Brau $(p<0.05)$ and between the $\mathrm{Oy}$ and the Lao $(p<0.01)$; the ADL scores of the Lao and Brau were not significantly different $(p>0.05)$ nor were any of the IADL scores significantly different among the three ethnic groups.

Details of ADL and IADL variables are shown in Tables 2 and 3, respectively. As shown, most of the respondents had no limitations in carrying out ADL activities. In contrast, many of the respondents had limitations in carrying out IADL activities especially shopping, phone usage and handling personal finances.

\section{Correlations}

Table 4 shows Spearman's correlations between nutritional status and selected independent variables. Only the results of variables that correlated with nutritional status in each ethnic group are shown.

These findings show that gender and educational level significantly correlated with nutritional status only among

Table 2 Ability of respondents to carry out activities of daily living activities

\begin{tabular}{llccc}
\hline Activity & Ability & $\begin{array}{c}\text { Oy } \\
(n=53)\end{array}$ & $\begin{array}{c}\text { Brau } \\
(n=41)\end{array}$ & $\begin{array}{c}\text { Lao } \\
(n=50)\end{array}$ \\
\hline Self-feeding & Needs assistance & $1(1.9)$ & $1(2.4)$ & $0(0)$ \\
& No assistance & $52(98.1)$ & $40(97.6)$ & $50(100)$ \\
Grooming & Needs assistance & $1(1.9)$ & $0(0)$ & $0(0)$ \\
& No assistance & $52(98.1)$ & $41(100)$ & $50(100)$ \\
Getting out of & Needs assistance & $8(15.1)$ & $5(12.2)$ & $1(2)$ \\
bed & No assistance & $45(84.9)$ & $36(87.8)$ & $49(98)$ \\
Going to toilet & Needs assistance & $3(5.7)$ & $1(2.4)$ & $1(2)$ \\
& No assistance & $50(94.3)$ & $40(97.6)$ & $49(98)$ \\
Movement in & Needs assistance & $7(13.2)$ & $7(17.1)$ & $3(6)$ \\
house & No assistance & $46(86.8)$ & $34(82.9)$ & $47(94)$ \\
Dressing & Needs assistance & $4(7.5)$ & $1(2.4)$ & $2(4)$ \\
& No assistance & $49(92.5)$ & $40(97.6)$ & $48(96)$ \\
Climbing & Needs assistance & $2(3.8)$ & $8(19.5)$ & $4(8)$ \\
stairs & No assistance & $51(96.2)$ & $33(80.5)$ & $46(92)$ \\
Bathing & Needs assistance & $1(1.9)$ & $1(2.4)$ & $0(0)$ \\
& No assistance & $52(98.1)$ & $40(97.6)$ & $50(100)$ \\
Holding stool & Needs assistance & $14(26.4)$ & $0(0)$ & $3(6)$ \\
& No assistance & $39(73.6)$ & $41(100)$ & $47(94)$ \\
Holding urine & Needs assistance & $14(26.4)$ & $1(2.4)$ & $2(4)$ \\
& No assistance & $39(73.6)$ & $40(97.6)$ & $48(96)$ \\
\hline Data ane pres & & &
\end{tabular}

Data are presented as the number (of respondents) with the percentage in parenthesis 
Table 3 Ability of respondents to carry out instrumental activities of daily living

\begin{tabular}{llccl}
\hline Activity & Ability & $\begin{array}{l}\text { Oy } \\
(n=53)\end{array}$ & $\begin{array}{l}\text { Brau } \\
(n=41)\end{array}$ & $\begin{array}{l}\text { Lao } \\
(n=50)\end{array}$ \\
\hline Phone usage & Needs assistance & $50(94.3)$ & $38(92.7)$ & $38(76)$ \\
& No assistance & $3(5.7)$ & $3(7.3)$ & $12(24)$ \\
$\begin{array}{c}\text { Movement } \\
\text { around } \\
\text { village }\end{array}$ & Needs assistance & $19(35.8)$ & $17(41.5)$ & $26(52)$ \\
Handling & No assistance & $34(64.2)$ & $24(58.5)$ & $24(48)$ \\
finances & Needs assistance & $34(62.2)$ & $22(53.7)$ & $25(50)$ \\
Housekeeping & No assistance & $19(35.8)$ & $19(46.3)$ & $25(50)$ \\
& Needs assistance & $9(17)$ & $15(36.6)$ & $19(38)$ \\
Shopping & No assistance & $44(83)$ & $26(63.4)$ & $31(62)$ \\
& Needs assistance & $34(64.2)$ & $26(63.4)$ & $29(58)$ \\
Meal & No assistance & $19(35.8)$ & $15(36.6)$ & $21(42)$ \\
preparation & Needs assistance & $12(22.7)$ & $19(46.3)$ & $25(50)$ \\
& No assistance & $41(77.4)$ & $22(53.7)$ & $25(50)$ \\
\hline
\end{tabular}

Data are presented as the number (of respondents) with the percentage in parenthesis

Table 4 Spearman's correlations between nutritional status (MNA scores) and selected variables

\begin{tabular}{|c|c|c|c|}
\hline \multirow[t]{2}{*}{ Variable } & \multicolumn{3}{|l|}{$R$} \\
\hline & Oy & Brau & Lao \\
\hline Age (years) & & $-0.420^{* *}$ & $-0.490^{* *}$ \\
\hline Gender & $-0.382^{* *}$ & - & - \\
\hline BMI $\left(\mathrm{kg} / \mathrm{m}^{2}\right)$ & $0.377 * *$ & $0.493 * *$ & $0.509 * *$ \\
\hline Reduced appetite & $-0.429 * *$ & $-0.795 * *$ & $-0.387 * *$ \\
\hline Number of meals & - & $0.482 * *$ & $0.546 * *$ \\
\hline Living conditions & - & - & $-0.295^{*}$ \\
\hline Food taboos & - & $-0.422 * *$ & - \\
\hline Education level & $0.337 *$ & - & - \\
\hline ADL & - & $0.354^{*}$ & - \\
\hline IADL & - & $0.702 * *$ & $0.478 * *$ \\
\hline GDS & - & $0.488 * *$ & - \\
\hline Neuropsychological stress & $0.510^{* *}$ & $0.616^{* *}$ & $0.280^{*}$ \\
\hline Common diseases & - & $0.466 * *$ & - \\
\hline
\end{tabular}

$B M I$ Body mass index, $A D L$ Activities of daily living, IADL Instrumental activities of daily living

* Significant at $p<0.05$

** Significant at $p<0.01$

the Oy respondents. Food taboos, ADL, the presence of acute illnesses and GDS correlated with nutritional status only among the Brau respondents, and living conditions correlation with nutritional status only among the Lao respondents. Age, number of meals and IADL correlated with nutritional status among both the Brau and Lao respondents, while BMI, neuropsychological stress and reduced appetite correlated with nutritional status in all three ethnic groups.
Table 5 Logistic regression between Mini nutritional assessment scores and selected variables

\begin{tabular}{lrrr}
\hline Variable & \multicolumn{3}{l}{ Beta } \\
\cline { 2 - 4 } & Oy & \multicolumn{1}{l}{ Brau } & \multicolumn{1}{c}{ Lao } \\
\hline BMI & $0.431^{* *}$ & $0.401^{* *}$ & $0.454^{* *}$ \\
Reduced appetite & $-1.154^{* *}$ & $-0.988^{* *}$ & $-0.958^{*}$ \\
Number of meals & $1.111^{* *}$ & $1.366^{* *}$ & $1.519^{* *}$ \\
Food taboos & & $-1.294^{*}$ & \\
IADL & & $0.293^{*}$ & $0.458^{* *}$ \\
Neuropsychological stress & $-2.248^{* *}$ & $-2.427^{* *}$ & \\
Common diseases & $-0.985^{* *}$ & $-0.862^{* *}$ & $-1.578^{* *}$ \\
\hline$R^{2}$ is $76.8,92.5$ and & &
\end{tabular}

$R^{2}$ is $76.8,92.5$ and $86.5 \%$ for the Oy, Brau and Lao, respectively

* Significant at $p<0.05$

** Significant at $p<0.01$

Predictors of nutritional status

Multiple logistic regression was used to determine the best predictors for nutritional status, and the results are shown in Table 5. Only the results of variables that predicted the nutritional status in each ethnic group are shown.

As shown, BMI, reduced appetite, low number of meals consumed daily and the presence of common diseases were the best predictors of nutritional status in all three ethnic groups. Neuropsychological stress only predicted nutritional status in the Oy and Brau respondents, functional capacity (IADL) only predicted nutritional status in the Brau and Lao respondents and food taboos predicted nutritional status only in the Brau respondents.

\section{Discussion}

In this study, we assessed the nutritional status, functional capacity and predictors of nutritional status of the community-dwelling elderly in two ethnic minority populations (Oy and Brau) and one main ethnic group (Lao) in southern Laos. A higher number of women than men participated in our study. Life expectancy at birth in Laos is 53.1 years for men and 57.2 years for women, which indicates that women have a higher odds of living longer than men [22].

Our study identified a prevalence of malnutrition for all respondents, irrespective of ethnicity, that is higher than that which has been reported among community-dwelling elderly $(0-8 \%)$ in other studies [23]. However, our results are similar to those reported for the prevalence of malnutrition in the hospitalised and institutionalised elderly $(0-74 \%)$ [23]. It is well-known that in most developing countries there are only a few services that are oriented towards the health and well-being of elderly persons and that even when available, these services are even less available to residents in rural areas. Our study was carried 
out in one of the most remote areas in southern Laos, where such services as care centers and nursing homes are nonexistent. Our results stress the need for these services to be aimed at helping the elderly within rural communities in developing countries, as these can be used to screen and treat malnutrition as early as possible.

Despite the fact that all respondents were living in Attapeu province, the Oy and Brau (ethnic minority) respondents had a significantly higher prevalence of malnutrition than the Lao respondents (ethnic majority). As mentioned earlier, in comparison to ethnic majority groups, ethnic minority groups in developing countries tend to live in poverty [13]. The Oy and Brau ethnic groups also speak a different language from the Lao, which presents a major obstacle when accessing medical care and markets. The villages in which these ethnic groups reside are located in the rural parts of Attapeu province, far from the town center, markets and hospitals. The Lao, on the other hand, have a better access to markets and health services and are generally more affluent than the Oy and Brau. Lao respondents also had two rice planting seasons, as opposed to the Oy and the Brau, who depend on one rice planting season. Consequently, the Lao respondents had a better odds of year-long rice sufficiency in comparison to the Oy and Brau respondents. Such circumstances could provide an explanation for the significantly better nutritional status of the Lao than of the Oy and Brau ethnic groups.

Inadequate food intake is the main cause of malnutrition [24]. Reduced appetite, fewer meals consumed daily and the presence of illness all result in a reduction in food intake. In our study, the best predictors of nutritional status in all three ethnic groups were BMI, reduced appetite, number of meals consumed daily and the presence of common diseases. Reduced appetite is known to affect the nutritional status of the elderly, as observed in a number of studies showing that reduced appetite predicts malnutrition and that a severe loss of appetite is associated with malnutrition [25, 26].

Although all respondents resided in the same province they belonged to different ethnic groups. This led us to hypothesise that a number of the predictors of nutritional status would be different. Our hypothesis was justified because, besides the aforementioned factors, a number of factors that affected the nutritional status varied by ethnicity, even within the ethnic minorities. This implies that indirect factors closely linked with belonging to a different ethnic group, such as access to resources, lifestyle and language barriers, can affect nutritional status. This result also suggests that area-specific-and not generalisedinterventions need to be implemented to significantly meet the needs of the elderly in multi-ethnic settings.

Research carried out in Attapeu province showed that traditional food behaviours and food taboos are the root causes of malnutrition in many minority populations in this province [27]. In our study, however, food taboos were shown to predict nutritional status only in the Brau ethnic minority. Information gathered from focus group discussions revealed that the some Oy respondents restricted themselves from eating fermented foods and meat from wild animals, while some Brau respondents did not consider eating fish and meat from wild animals. The main foods consumed in Laos are rice, fish and vegetables [28]; meat is not frequently consumed. Fish would clearly be the main source of protein in these two ethnic minority groups because it is readily available in rivers, ponds and rice fields. Ethnic restrictions on fish consumption would therefore have an effect on nutritional status and thereby indicates why food taboos predicted nutritional status only in the Brau respondents.

Maintenance of functional capacity is an important indicator of health among the elderly; the loss of these capacities leads to a rise in morbidity and mortality [29]. Unlike other studies, in which the nutritional status was predicted by functional capacity $[3,5,6]$, our study only showed functional capacity (IADL) to be a predictor of nutritional status in the Lao and Brau ethnic groups. ADL did not predict nutritional status in any of the three ethnic groups, most likely because most of the respondents were able to carry out important tasks, such as feeding, grooming and getting into and out of bed (Table 2). The negative effect on nutrition is compounded when elderly persons are unable to carry out the aforementioned tasks and lack access to help from relatives or care services. However, because most of the respondents were able to do these tasks on their own, it could be argued that this explains why ADL did not predict nutritional status in any of the ethnic groups studied here.

Instrumental activities of daily living, on the other hand, consist of such activities as shopping, ability to handle finances and meal preparation. Studies have shown that limitations in such activities as meal preparation can affect nutritional status [3]. As shown in Table 3, even though most of the respondents in all three ethnic groups were able to shop without assistance, more Brau and Lao respondents than Oy respondents required assistance with food preparation. An inability to cook for oneself affects food choices and increases one's vulnerability, as one can only eat what is provided. This is possibly why IADL predicted the nutritional status in Brau and Lao respondents, but not in Oy respondents.

One of the limitations of our study is that we were unable to collect data on food consumption and household incomes. This could have given a clearer picture of the predictors of nutritional status of the respondents. Future research in southern Laos should include these aspects to further clarify the predictors of malnutrition in these communities. 


\section{Conclusion}

Our findings show a high prevalence of malnutrition in these three rural ethnic communities and a high level of dependence within the instrumental activities of daily living. These results stress the urgent need for area-specific interventions aimed at improving the nutritional status, functional capacity and resultant quality of life of the elderly living in areas with diverse populations; such as in countries as Laos with many diverse ethnic groups. Such services, as well as sensitization, are necessary for the promotion of healthy ageing. The health status of the elderly should also be documented and incorporated into the Laotian government's healthcare system, as the elderly are becoming an increasingly important and vulnerable portion of society in Laos.

Acknowledgments This study was supported by funding from the Japanese Ministry of Education, Culture, Sports, Science and Technology (\#20530465). The authors would like to thank the Laos National Institute of Public Health (NIOPH) staff, as well as the elderly who participated in this study.

Conflict of interest The authors have no conflicting interests.

\section{References}

1. Ghisla MK, Cossi S, Timpini A, Baroni F, Facchi E, Marengoni A. Predictors of successful rehabilitation in geriatric patients: subgroup analysis of patients with cognitive impairment. Aging Clin Exp Res. 2007;19:417-23.

2. Millán-Calenti JC, Gandoy-Crego M, Antelo-Martelo M, LópezMartinez M, Riveiro-López MP, Mayán-Santos JM. Helping the family carers of Alzheimer's patients: from theory to practice. A preliminary study. Arch Gerontol Geriatr. 2000;30:131-8.

3. Oliveira MR, Fogaca KC, Leandro-Merhi VA. Nutritional status and functional capacity of hospitalized elderly. Nutr J. 2009;8:54.

4. Leidy NK. Functional status and the forward progress of merrygo-rounds: Toward a coherent analytical framework. Nurs Res. 1994;43:196-202.

5. Andre MB, Dumavibhat N, Ngatu NR, Eitoku M, Hirota R, Suganuma N. Mini nutritional assessment and functional capacity in community-dwelling elderly in Rural Luozi, Democratic Republic of Congo. Geriatr Gerontol Int. 2013;13:35-42.

6. Romagnoni $\mathrm{F}$, Zuliani G, Bollini $\mathrm{C}$, et al. Disability is associated with malnutrition in institutionalized elderly people. The I.R.A. Study. Istituto di Riposo per Anziani. Aging (Milano). 1999;11:194-9.

7. World Food Programme. In: World Food Programme annual report. Rome, World Food Programme. 2005.

8. Miyoshi M, Phommasack B, Nakamura S, Kuroiwa C. Nutritional status of children in rural Lao PDR: who are the most vulnerable? Eur J Clin Nutr. 2005;59:887-90.

9. Manilay P, Moazzam A, Fumihiro Y, Phengxay S, Kuroiwa C, Hiroshi U. Risk factors for protein-energy malnutrition in children under 5 years: study from Luangprabang province, Laos. Pediatr Int. 2007;49:260-5.

10. Matsubayashi K. Aging of population and its related subjects in Asia. Jpn J Geriatr. 2002;39:355-63.
11. Galanos AN, Pieper CF, Cornon-Humntley JC, Balles CW, Pillebaum CG. Nutrition and function: is there a relationship between body mass index and functional capabilities of community-dwelling elderly? J Am Geri Soc. 1994;42:368-73.

12. Manandhar MC, Ankelsaria PS, Myatt M, Ismail SJ. Undernutrition and functional ability amongst poor elderly people in urban India. J Nutr Health Ageing. 1997;1:75-6.

13. International fund for agricultural development (IFAD). In: Country technical notes on indigenous peoples' issues Lao People's Democratic Republic. International fund for agricultural development (IFAD), Rome, 2012.

14. Vellas B, Guigoz Y, Garry PJ, Nourhashemi F, Bennahum D, Lauque S, et al. The Mini nutritional assessment (MNA) and its use in grading the nutritional state of elderly patients. Nutrition. 1999;15:116-22.

15. Bauer JM, Kaiser MJ, Anthony P, Guigoz Y, Sieber CC. The Mini nutritional assessment-its history, today's practice, and future perspectives. Nutr Clin Pract. 2008;23:388-96.

16. Baweja S, Agarwal H, Mathur A, et al. Assessment of nutritional status and related risk factors in community dwelling elderly in western Rajasthan. J Indian Acad Geriatr. 2008;4:5-13.

17. Kabir ZN, Ferdous $T$, Cederholm $T$, et al. Mini nutritional assessment of rural elderly people in Bangladesh: the impact of demographic, socio-economic and health factors. Public Health Nutr. 2006;9:968-74.

18. Vedantam A, Subramanian V, Rao NV, John KR. Malnutrition in free-living elderly in rural south India: prevalence and risk factors. Public Health Nutr. 2010;3:1328-32.

19. Barrocas A, Bistrian BR, Blackburn GL, Chernoff R, Lipschitz DA, Cohen D, Dwyer J, Rosenberg IH, Ham RJ, Keller GC, Wellman NS, White J. Appropriate and effective use of the NSI checklist and screens. J Am Diet Assoc. 1995;95:647-8.

20. Lawton MP, Brody EM. Assessment of older people: self-maintaining and instrumental activities of daily living. Gerontologist. 1969;9:179-86.

21. Collin C, Wade DT, Davies S, et al. The Barthel ADL Index: a reliability study. Int Disabil Stud. 1988;10:61-3.

22. The World Fact Book. CIA, New York. 2005. http://www.cia. gov/cia/publications/factbook Accessed 14 June 2005.

23. Guigoz Y. The Mini nutritional assessment (MNA) review of the literature-what does it tell us? J Nutr Health Aging. 2006; 10:466-85.

24. Bo M, Massaia M, Raspo S, Bosco F, Cena P, Molaschi M, Fabris F. Preventive factors of in-hospital mortality in older patients admitted to a medical intensive care unit. J Am Geriatr Soc. 2003;51:529-33.

25. Mowe M, Bohmer T. Reduced appetite. A predictor for undernutrition in aged people. J Nutr Health Aging. 2002;6:81-3.

26. David RT, Carolyn DZ, Margaret-Mary W, Kelly CC, Cecelia L, Syed T, John EM. Malnutrition in subacute care. Am J Clin Nutr. 2002;75:308-13.

27. Mekong Wetlands Biodiversity Conservation and Sustainable Use Programme. Attapeu situation report. Vientianne, Lao PDR. 2006.

28. Barennes H, Simmala C, Odermatt P, Thaybouavone T, Vallee J, Martinez-Ussel B, Newton PN, Strobel M. Postpartum traditions and nutrition practices among urban Lao women and their infants in Vientiane, Lao PDR. Eur J Clin Nutr. 2009;63:323-31.

29. Stuck AE, Walter JM, Nikolaous T, Bula CJ, Hhmann C, Beck JC. Risk factors for functional status decline in community living elderly people; a systematic literature review. Soc Sci Med. 1999;48:445-69. 